\title{
MODELING THE INFLUENCE OF RIVER FLOW AND SALINITY INTRUSION IN THE MEKONG RIVER ESTUARY, VIETNAM
}

\author{
Doan Quang Tri $^{1}$, Nguyen Cao Don ${ }^{2}$, Chen Yi Ching ${ }^{1}$ and Pawan Kumar Mishra ${ }^{3}$
}

\begin{abstract}
In this study, a hydrodynamic and solute transport model was applied to evaluate the effect of dredging on salinity intrusion in the estuary of the Mekong River, southern Vietnam. The model was calibrated and validated with available hydrographic measured data in 2000, 2004 and 2009. The flow and salinity at different positions in the river were dynamically assessed using the hydrodynamic and advection dispersion models. The factors of velocity, flow, water level providing flow boundary parameter for two-dimension model were calculated for both dry and flood season, while salinity was calculated only for the dry season to evaluate the impact of dredging to salinity intrusion process. The results of salinity intrusion simulation for 15 days show that the impact of dredging only occurs in the Quan Chanh Bo channel and does not affect the large river system. The minimum and maximum salinity concentrations along Quan Chanh Bo channel were predicted to be in the range of 2.0-6.0PSU.
\end{abstract}

Keywords: Hydrodynamic model, advection-dispersion model, salinity intrusion, Mekong River Estuary, flood and dry season.

\section{INTRODUCTION}

Assessment of water resources is an important task in water resources planning and management. Frequently, hydrologic models with effective tools can do the task. However, with water system strongly affected by tides and salinity intrusion, these tools are limited. The characteristic of flows and salinity intrusion such as the discharge distribution among the river branches and the isohalines for certain water salinities are then derived from the simulated results and observed data. In fact, the variation of upstream inflow affects the downstream flow and salinity intrusion. It means that the hydrodynamic and advection-dispersion model are required to simulate the river network. Due to these reasons, the hydrodynamic and advection-dispersion models have been applied in the studies on flow and salinity intrusion in the Mekong Delta (Zanobetti et al. 1970; Van Parreeren 1974; Cunge 1975; Abbott and Cunge 1975; Alcausin 1980; Quang and Ngoc 1987; Thoi 1987; NEDECO 1991a; Cong 1992; Thoi 1993; Tingsanchali and Thoi 1993; Thoi 1994; Wolanski 1996; Thuy and Dac 2000; Dong 2000; Sam 2006; Massaki et al. 2007; Kotera 2008).
In order to assess the river water resources in the Mekong Delta by mathematical modeling, the hydrodynamic and advection-dispersion models should be applied whenever there are any changes of boundary conditions. The model functions consist of tidal elevations along the downstream boundaries and freshwater discharges from the upstream boundaries of the Mekong River with measured data in 2000, 2004, and 2009. Hydrodynamic (HD) and AdvectionDispersion (AD) modules were used for this study. The objective is to simulate the hydrodynamic regime in the river flow and salinity intrusion at specific locations in the network system for water management purpose under hydrologic conditions of upstream inflow and tides at the river estuary.

\section{MATERIAL AND METHODS}

Description of Study Site

The Mekong Delta in Vietnam is located at the most downstream end of the Lower Mekong Basin (Fig.1). It is a flat and low-lying area of 3.9 million hectares. The delta is located in the monsoon tropical semi-equatorial

\footnotetext{
${ }^{1}$ Department of Environmental Engineering, DaYeh University, doanquangtrikttv@gmail.com, TAIWAN

${ }^{2}$ IALT member, Department of Water Resources Engineering, Water Resources University, Hanoi, VIETNAM

${ }^{3}$ Department of Wood Science, Mendel University In Brno, CZECH Republic

Note: Discussion on this paper is open until December 2014
} 
climate with two distinct seasons in a year. The hydraulic and hydrological regimes in the Mekong Delta depend on upstream discharge, local rainfall and tidal movement of the South China Sea and the Western Sea (Gulf of Thailand). However, during the dry season when the salinity intrusion problems prevail, local rainfall plays a very minor role (Le 2006). Thus, the delta is mostly affected by both the river flows and the tidal movements. The discharge distribution between two branches of the river: the Mekong (i.e. Tien) and Bassac at Tan Chau and Chau Doc is unequal. An annual ratio for Tan Chau/Chau Doc could be roughly estimated at $83 \% / 17 \%$. The ratio is lower in the flood season $(80 \% / 20 \%)$ and higher in the dry season $(84-86 \% / 14-$ $16 \%$ ) (Le 2006). The Vam Nao channel is a connecting river and it supplies water for the Bassac River. The role of the Vam Nao channel is to balance the water flow between the Bassac and Tien River and it plays an important role in the hydraulic regime of the entire Mekong Delta.

The tidal movement at the various estuarine mouths has an important impact on drainage and salinity intrusion. The coastal region from Vung Tau to the $\mathrm{Ca}$ Mau cape is affected by tide of the South China Sea, while the coastal region from the $\mathrm{Ca}$ Mau cape to $\mathrm{Ha}$ Tien is affected by the tide of the Western Sea (Gulf of Thailand). Tides in the South China Sea have a mixed diurnal and semi-diurnal character with a period of 12.25 hours. There are generally two troughs and two peaks during a day, but their relative height varies over a fortnight. The tidal range is relatively high, about 2.5 $3.5 \mathrm{~m}$ depending on the location (Le 2006; Tang 2002).

Exchange between the Mekong River and the sea causes a number of problems, especially in salinity and sedimentation. Every year in the dry season, agricultural areas in the Mekong Delta are affected by salinity, amounting to $1.7-2.1$ million ha out of 3.5 million ha in total (MRC 2004). A number of projects for salinity control were implemented. They can be listed as: Go Cong (to protect 26,000 ha of agricultural areas from salinity), Tiep Nhat (11,000 ha), South Mang Thit (293,000 ha), Quan Lo - Phung Hiep (290,000 ha), Western Sea coast (50,700 ha) etc. Nowadays, salinity affects only $800,000-900,000$ ha every year. However, fresh water intakes in the Mekong branches are usually affected by salt-water intrusion. Every year, these intakes have to be closed for quite long periods (from some weeks to one or two months) to prevent salinity intrusion (Nguyen and Nguyen 1999).
Model

\section{Model Description}

MIKE 11 model is a dynamic, one-dimensional modeling tool for the design, management, and operation of complex river systems. This software has four editors including simulation, river network, cross sections, and boundary conditions and various modules including hydrodynamic (HD), the Advection Dispersion (AD), Water Quality (WQ), runoff and rainfall, sediment transfer, and flood forecasting (DHI 2007). Onedimensional equations governing the river flow are known as Saint-Venant equations (Shooshtari 2008). These are written as follows:

$$
\begin{aligned}
& \frac{\partial A}{\partial t}+\frac{\partial Q}{\partial x}=q \\
& \frac{\partial Q}{\partial t}+\frac{\partial\left(\alpha \frac{Q^{2}}{A}\right)}{\partial x}+g A \frac{\partial h}{\partial x}+\frac{g Q|Q|}{C^{2} A R}=0
\end{aligned}
$$

where $\mathrm{Q}$ is discharge, $\mathrm{A}$ is the cross-sectional area, $\mathrm{q}$ is lateral inflow, $\mathrm{C}$ is Chezy roughness coefficient, $\mathrm{R}$ is hydraulic radius, and $\alpha$ is momentum correction coefficient. Based on differential equations and finite difference method, flow depth (h-points) and flow discharge (Q-points) at nodes are calculated (Fig.2).

The advection-dispersion equation in MIKE11 model is as follows. This equation considers two transport mechanisms of advective and dispersive transports.

$$
\frac{\partial A C}{\partial t}+\frac{\partial Q C}{\partial x}+\frac{\partial}{\partial x}\left(A D \frac{\partial C}{\partial x}\right)=-A K C+C_{2} q
$$

where $\mathrm{C}$ is the concentration, $\mathrm{D}$ is the dispersion coefficient, $\mathrm{A}$ is the cross-sectional area, $\mathrm{K}$ is the linear decay coefficient, $\mathrm{C}_{2}$ is the source/sink concentration, $\mathrm{q}$ is the lateral inflow discharge, $\mathrm{x}$ is the space coordinate, and $\mathrm{t}$ is the time coordinate.

The solution of the equations of continuity and momentum is based on an implicit finite difference scheme developed by (Abbott and Ionescu 1967). The finite difference scheme used in MIKE 11 (6-point Abbott scheme), allows Courant numbers up to 10-20 if the flow is clearly sub-critical (Froude number less than 1). A graphical view of this method showed as below (Fig.3). As we can see at $n+1 / 2$ step the model bring data from steps $\mathrm{n}$ and $\mathrm{n}+1$, so unknowns will obtain simultaneously for each time step. MIKE 11 model used implicit difference method to solve the problem and there is no limitation about computational ability (Price 2009). 


\section{Materials Model}

The HD module was defined by two flow boundaries in Kratie and Great Lake. The flow at another boundary was not significant for the Mekong River System. The water level data were collected from the national hydrometeorological stations. Thus, the data ensures reliability for calculation and calibration model. The water level at the estuary boundary is the measured data or predicted an hour water level. Water-level measurement applications setting for five lower boundaries are located at Vam Kenh (Tieu estuary), Binh Dai (Dai estuary), An Thuan (Ham Luong estuary), Ben Trai (Co Chien estuary), and My Thanh (My Thanh, Dinh An, Tran De estuary). The salinity of the upstream flow boundary is zero. The salinity at the estuary is estimated following the coastal climate documentation and measured data.

The data were used as the database for the hard boundary of model as follows:

+ The topography of the Bassac estuary, Quan Chanh Bo estuary and surrounding the study areas surveyed by the Port coast on 4/2009;

+ The topographic Atlas of Bassac River and Tien River by the Mekong River Commission issued in 1998 with the scale 1:20,000;

+ The DEM map of Mekong River Basin by the Mekong River Commission issued in 2003;

+ The document design of irrigation construction and the transportation of the downstream areas of Mekong River Basin are stored at the Institute of Southern Irrigation Science until 2002;

The study scope of modeling was built for all downstream of Mekong River Network in Fig.4. There are totally 3,775 cross-sections of the river system and channels. The rive network was digitized based on the satellite imagery about 66 river branches. The number of calculated nodes is estimated about 17,000 nodes. The diffusion coefficient was chosen for all branches with $\mathrm{D}$ $=500 \mathrm{~m}^{3} / \mathrm{s}$, except Quan Chanh Bo channel with $\mathrm{D}=$ $800 \mathrm{~m}^{3} / \mathrm{s}$. The time step for hydraulic model (HD) is $\Delta \mathrm{t}=$ $5 \mathrm{~min}$. The time step for advection-dispersion (AD) is $\Delta t$ $=30 \mathrm{~s}$.

The influences of rainfall, evaporation, infiltration, groundwater, winds were estimated according to the national hydro-meteorological stations on the downstream of Mekong River Basin (Fig.5). These stations applied for model calibration and validation.

\section{RESULTS AND DISCUSSIONS}

Model Calibration and Validation

Based on the measured data, the hydraulic model is calibrated according to the measured data in the dry season months and the rainy season months in 2000 and 2004. The calibration parameters of hydraulic model are presented on eight hydro-meteorological stations. The list of hydro-meteorological stations was applied for model calibration and validation showed in Table 1 . The positions of measured salinity serving validated model are showed in Fig.6.

After calibrating model, we must use independent observation sequences with the sequence using in calibration to validate the model. The hydraulic parameters of the calibration process are used in the model validation process. If the results of validation process show that the error is within acceptable limitation, the model is applied to forecast demand. To ensure randomness and assess the suitability of the calculated parameters, the measured data strings on September 2004 and April 2009 are used to validate the model. The model was calibrated and validated in three cycles in Table 2.

Table 1: The hydro-meteorological stations applied to calibrate and validate water level and flow

\begin{tabular}{ccccc}
\hline No. & Station & River & 2000 & 2004 \\
\hline 1 & Chau Doc & Bassac & Z & Z \\
2 & Can Tho & Bassac & Z,Q & Z,Q \\
3 & Dai Ngai & Bassac & Z & Z \\
4 & Tan Chau & Tien & Z & Z \\
5 & Vam Nao & Vam Nao & Z & Z \\
6 & My Thuan & Tien & Z,Q & Z,Q \\
7 & My Tho & Tien & Z & Z \\
8 & Tra Vinh & Co Chien & Z & Z \\
\hline
\end{tabular}

Note: Z: water level; $Q$ : flow

Table 2: The simulated cycles applied to calibrate and validate the model

\begin{tabular}{|c|c|c|}
\hline Time & Season & $\begin{array}{c}\text { Calibration } \\
\text { and validation }\end{array}$ \\
\hline March 2000 & Dry & $\begin{array}{l}\text { Calibrated } \\
\text { water level, flow }\end{array}$ \\
\hline September 2000 & Rainy & $\begin{array}{l}\text { Calibrated } \\
\text { water level }\end{array}$ \\
\hline April 2004 & Dry & $\begin{array}{l}\text { Calibrated } \\
\text { salinity }\end{array}$ \\
\hline September 2004 & Flood & $\begin{array}{l}\text { Validation } \\
\text { flow }\end{array}$ \\
\hline April 2009 & Dry & $\begin{array}{l}\text { Validated } \\
\text { water level, salinity }\end{array}$ \\
\hline
\end{tabular}

- The results of comparison between simulated and measured water level in 2000 and 2009 are presented in Fig. 7 to Fig. 15. 
- The results of comparison between simulated and measured flow in 2000 and 2004 are presented in Fig.16 to Fig. 19.

- The results of comparison between simulated and measured salinity in 2004 and 2009 are presented in Fig.20 to Fig.25.

\section{Assessment of Results}

The water level was calibrated at six stations on March 2000 such as Tan Chau, Chau Doc, Vam Nao, Can Tho, Dai Ngai and My Tho (Figs.7 to 12). The water level was validated at three stations on April 2009 such as Chau Doc, Tan Chau and Dai Ngai (Figs.13 to 15). The results of calculated and measured water level data are agreement vibration amplitude, absolute value and the tide phases. By editing Nash-Sutcliffe criterion (Nash and Sutcliffe 1970) we have the results of water level calibration and validation. The calibration results of simulated and measured water level data with NashSutcliffe ranges from 0.84 to 0.95 . The validation of calculated and measured water level data with NashSutcliffe ranges from 0.83 to 0.87 . This demonstrates that the water level data boundary in the estuarine (including tidal fluctuations and annual average water level) is reliable.

The flow calibration and validation used the flow at two stations Can Tho and My Thuan on March 2000 and September 2004. The results of calibrated and validated flow are presented from Figs.16 to 19. The results of simulated flow were not found to be as good as the water level simulation, while ensuring about phase. The deviation between the measured and simulated in calibrated and validated process with Nash-Sutcliffe criterion ranges from 0.8 to 0.89 . It should be noted that the measured flow data has a relative accuracy. Because measured flow time in each cross-section can be extended for an hour.

The salinity was calibrated at four stations such as Dai Ngai, Tra Vinh, My Tho and Hoa Binh on April 2004 (Figs.20 to 23). The salinity was validated at two positions S1 and S2 on April 2009 (Figs.24 and 25). The results revealed that in the calibration and validation case, the salinity between calculated and measured have conformity about phase and amplitude with NashSutcliffe criterion arrangement from 0.67 to 0.79 . However, the deviation about the results of calculated salinity is greater than the hydraulic calculation results. The qualitative distribution of the salinity measurement stations along the river decreases with the upstream direction. Salinity in the measurement stations up and down almost the same phase with the tide phase.
Scenarios Development

The factors of velocity, flow, water level and salinity in the river areas have been used in the MIKE 11 model. To provide flow boundary for MIKE 21 model, the factors of velocity, flow, water level were calculated for both dry and flood season, while salinity was calculated for the dry season to evaluate the impact of dredging to salinity intrusion process. The simulation scenarios are presented as follows:

Scenario 1: In case of flood in the upstream (provided the results of flow boundary for MIKE 21 models to predict the sediment movement).

+ The flow in the upstream corresponding to the discharge of flood peak in 2000;

+ The water level in the estuary is the water level of the typically tidal during flood season includes both semi-diurnal and diurnal regime (September);

Scenario 2: In case of minimized flow in the upstream (provided the results of flow boundary for MIKE 21 to predict the sediment movement and assess salinity intrusion).

+ The flow in the upstream is corresponding to the minimum flow in 1998;

+ The water level in the estuary is the water level of the typically tidal in the dry season includes semidiurnal and diurnal regime (April);

The Simulation Results

Scenario 1: estimated distribution of flow along Quan Chanh Bo channel from the 1 day simulation of the flood flow in the existing conditions and after dredging are presented in Figs.26 and 27.

Fig.26 shows range of water distribution in the Quan Chanh Bo channel is about $10 \mathrm{~km}$ from Dai An estuary. This is consistent with the actual conditions. Fig.27 shows that after escaping Tat channel and channel flow dredging, the water distribution position in Quan Chanh Bo channel tended to move toward the Dai An estuary. Fig.28 shows the distribution of maximum and minimum flow along Quan Chanh Bo channel in whole simulation period of 28 days (673 hours). The maximum outflow did not change about $420 \mathrm{~m}^{3} / \mathrm{s}$ before and after dredging at Dai An estuary. The maximum outflow decreased from $1,460 \mathrm{~m}^{3} / \mathrm{s}$ to $1,450 \mathrm{~m}^{3} / \mathrm{s}$ and the largest inflow increased from $1,690 \mathrm{~m}^{3} / \mathrm{s}$ to $1,780 \mathrm{~m}^{3} / \mathrm{s}$ at Lang Chim estuary. The inflow and outflow at Tat channel corresponding is $630 \mathrm{~m}^{3} / \mathrm{s}$ and $610 \mathrm{~m}^{3} / \mathrm{s}$.

The flow changes can be explained by the tidal wave propagation process through Tat channel. It changes the surface slope and changes the flow distribution. 


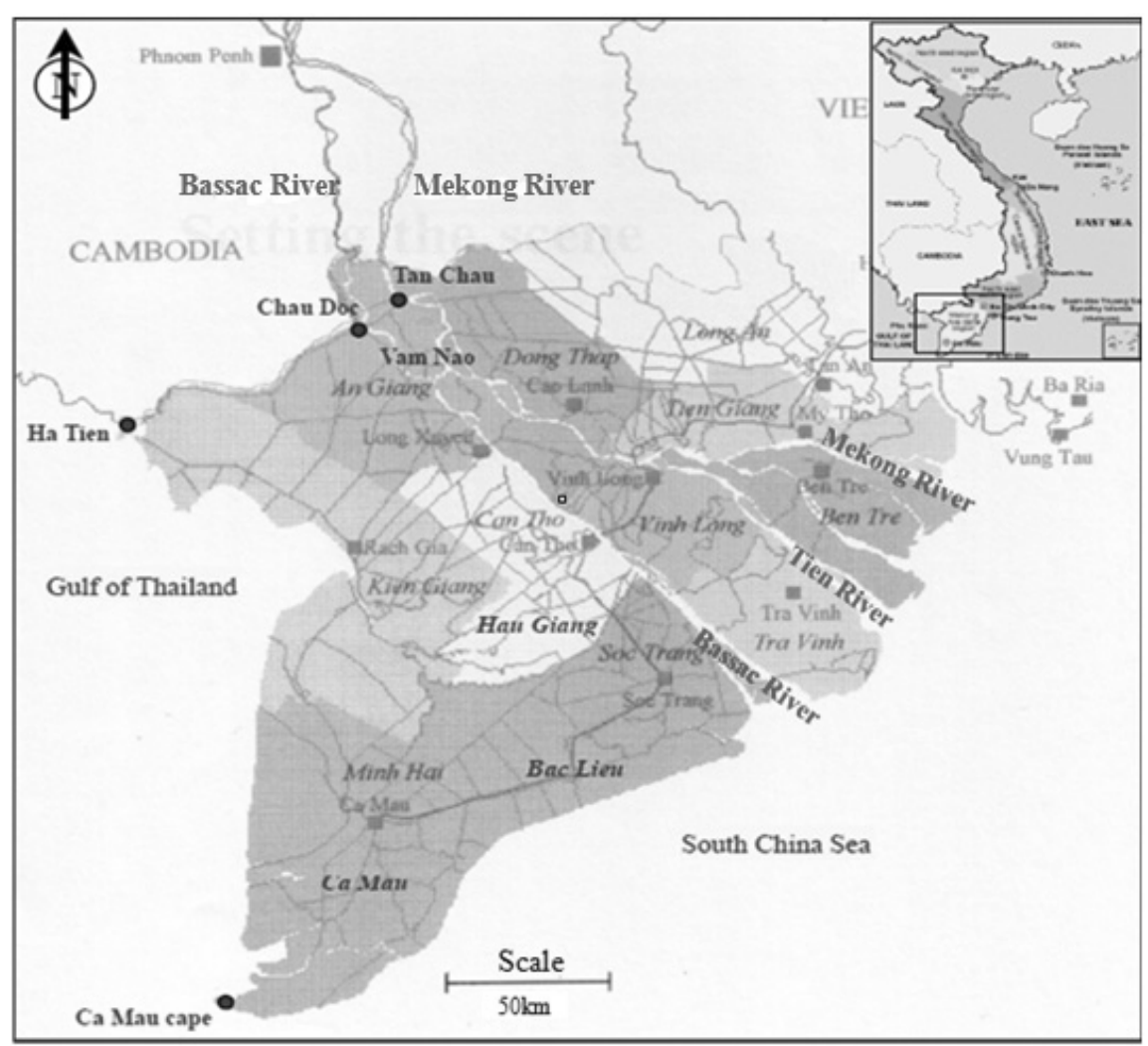

Fig. 1 Location map of Mekong Delta

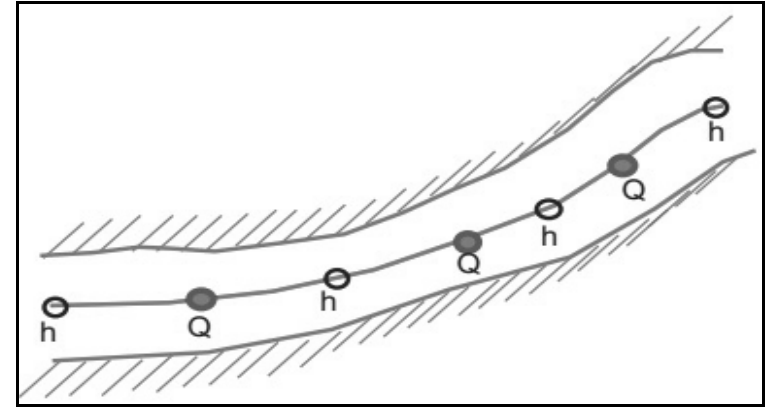

Fig. 2 Schematic nodding of h-points and Q-points for a river section in MIKE11 model (Eaton and Franson, 2005)

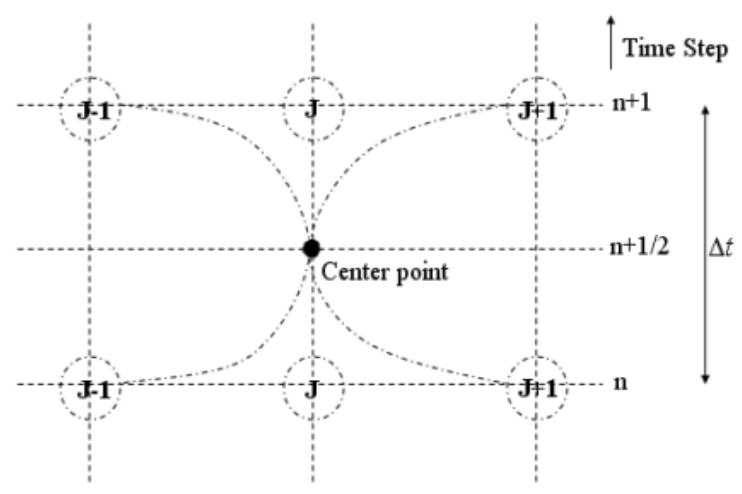

Fig. 3 Centered 6-point Abbott scheme

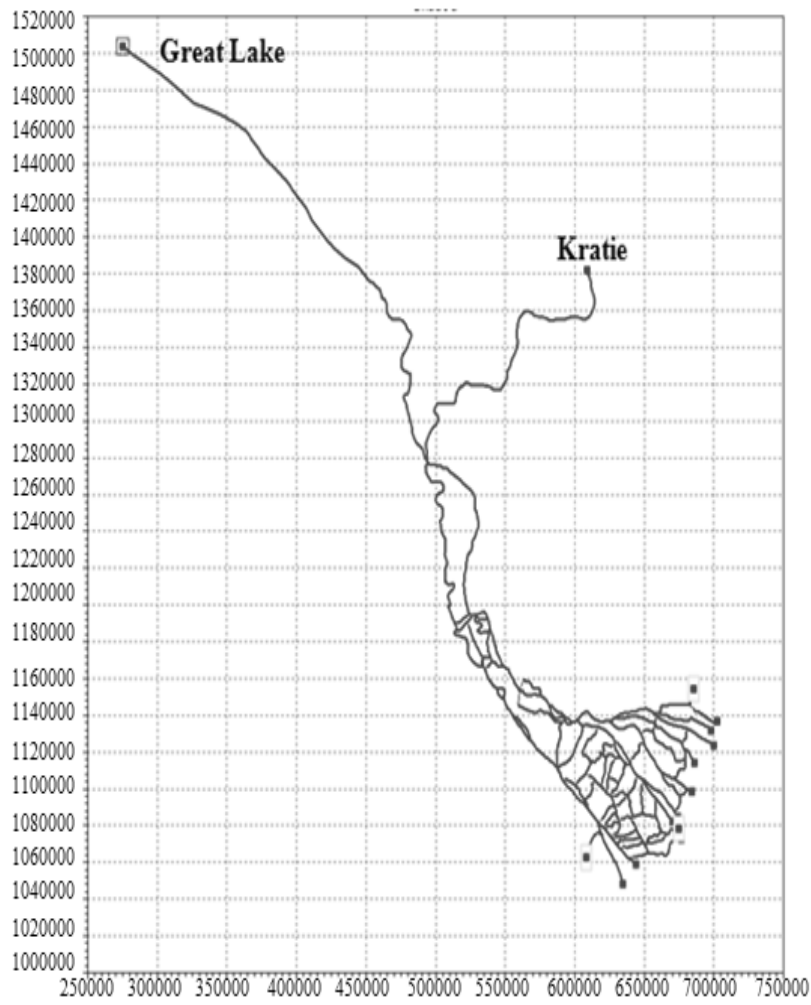

Fig. 4 Hydrodynamic network one-dimension (MIKE 11) 


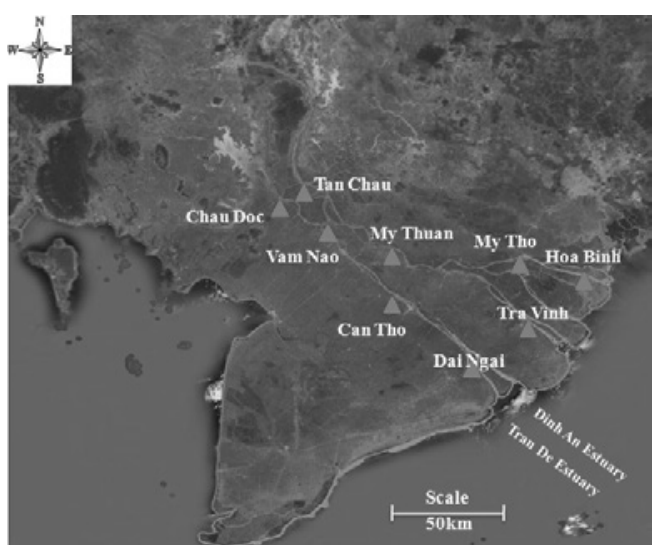

Fig. 5 Hydro-meteorological stations applied to calibrate and validate the model

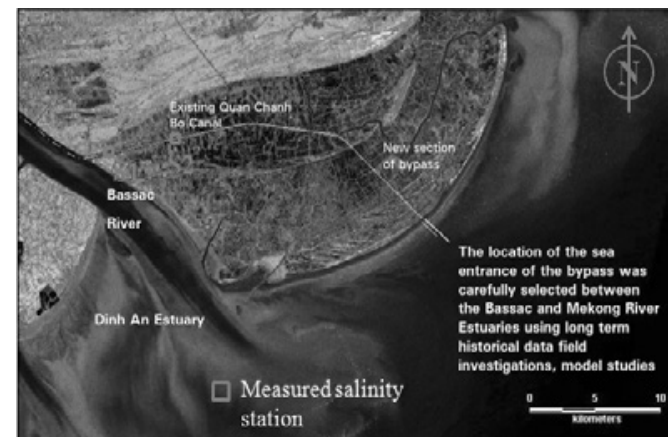

Fig. 6 Measured salinity positions

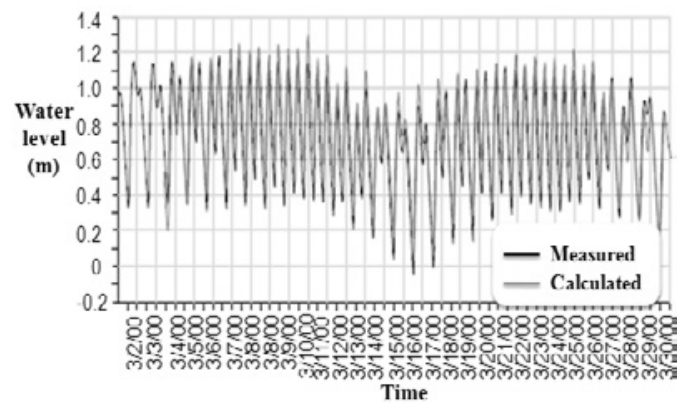

Fig. 7 Calibration of calculated and measured water level at Chau Doc station on March 2000 with NASH = 0.90

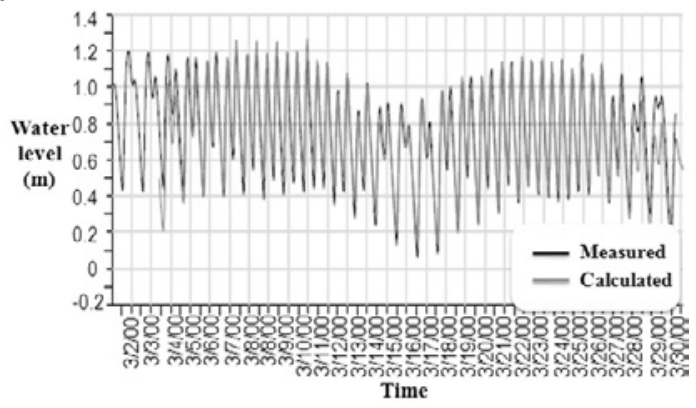

Fig. 8 Calibration of calculated and measured water level at Tan Chau station on March 2000 with NASH $=$ 0.89

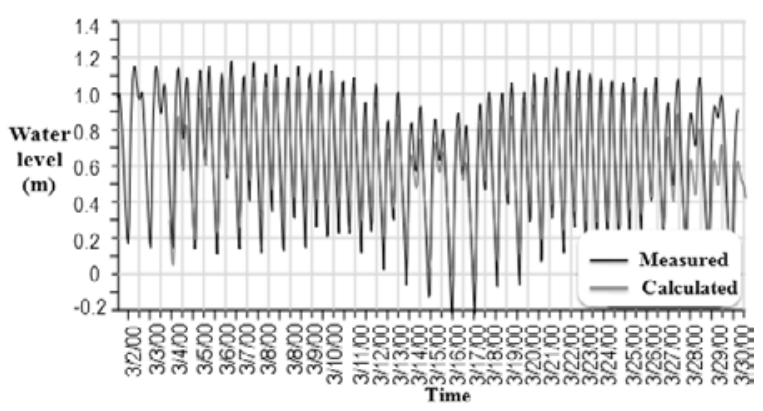

Fig. 9 Calibration of calculated and measured water level at Vam Nao station on March 2000 with NASH = 0.87

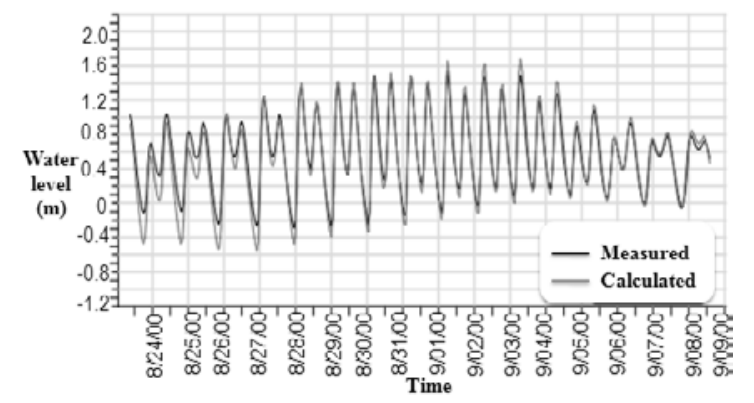

Fig. 10 Calibration of calculated and measured water level at Can Tho station on September 2000 with NASH $=0.90$

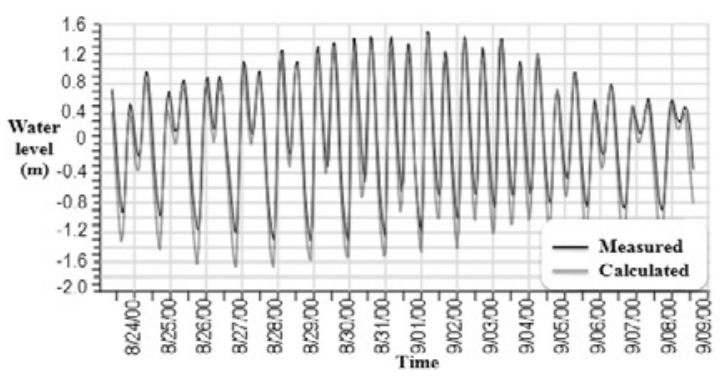

Fig. 11 Calibration of calculated and measured water level at Dai Ngai station on September 2000 with NASH $=0.84$

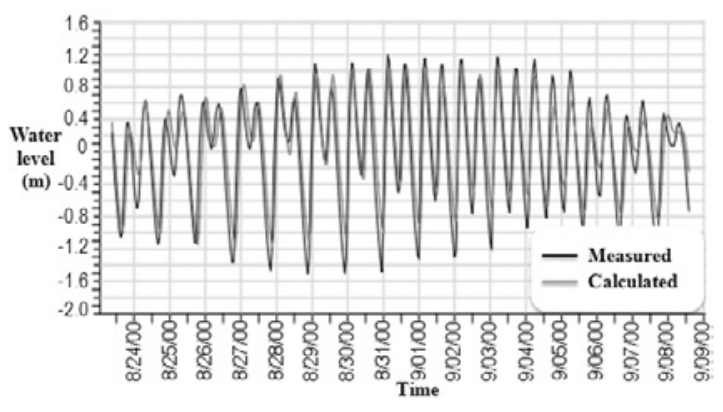

Fig. 12 Calibration of calculated and measured water level at My Tho station on September 2000 with NASH $=0.95$ 


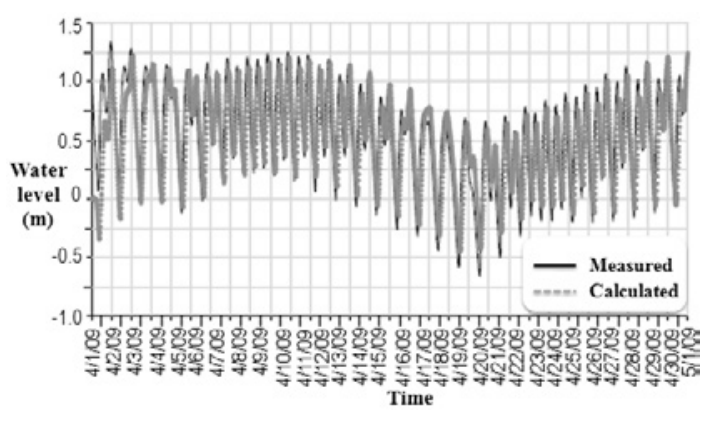

Fig. 13 Validation of calculated and measured water level at Chau Doc station on April 2009 with NASH = 0.83

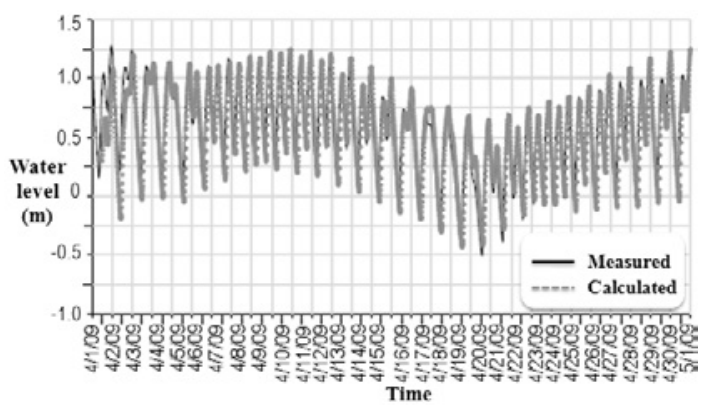

Fig. 14 Validation of calculated and measured water level at Tan Chau station on April 2009 with NASH = 0.87

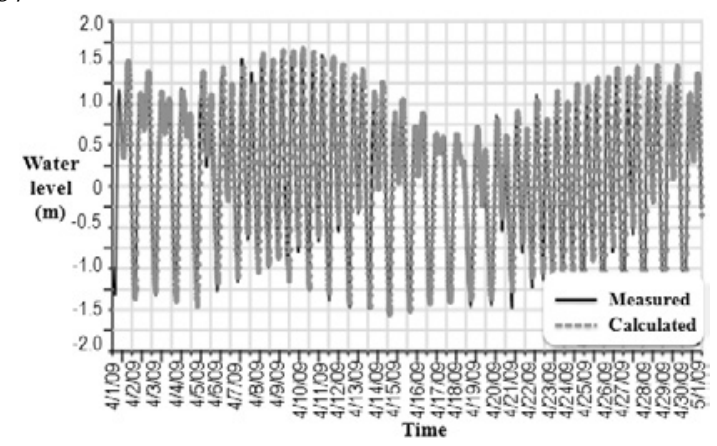

Fig. 15 Validation of calculated and measured water level at Dai Ngai station on April 2009 with NASH = 0.85

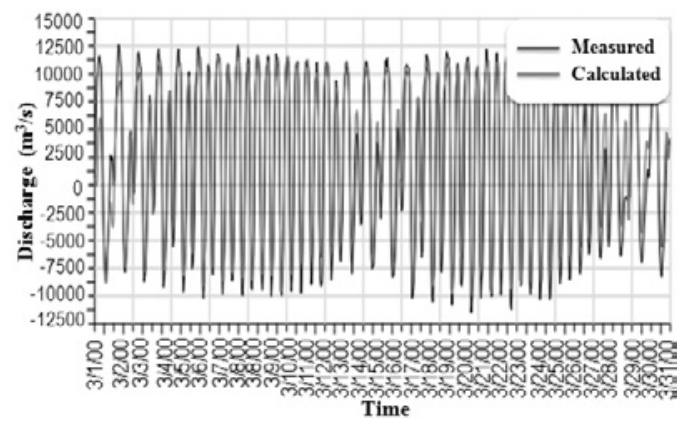

Fig. 16 Calibration of calculated and measured flow at Can Tho station on March 2000 with NASH $=0.89$

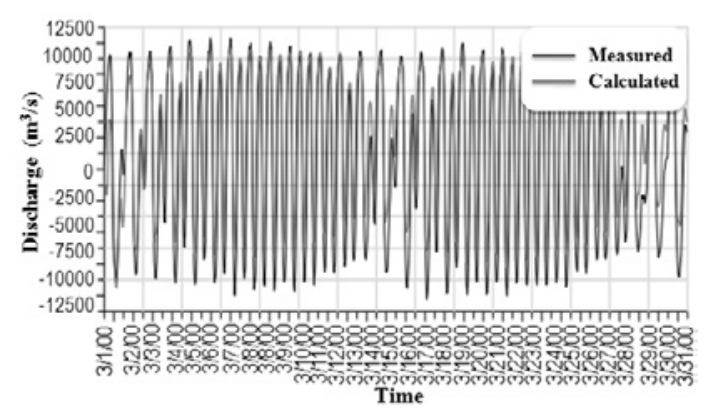

Fig. 17 Calibration of calculated and measured flow at My Thuan station on March 2000 with NASH $=0.87$

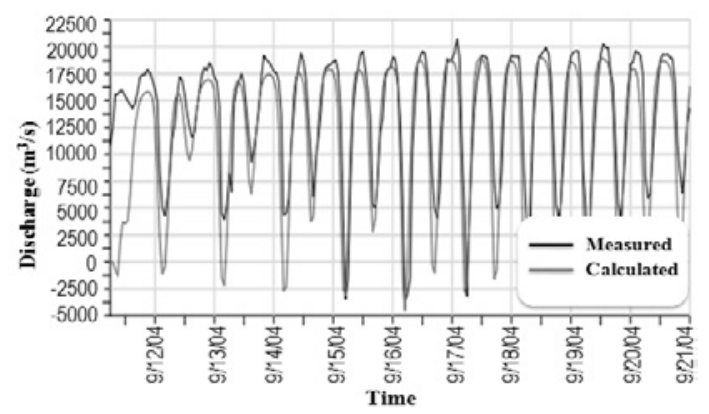

Fig. 18 Validation of calculated and measured flow at Can Tho station on September 2004 with NASH $=0.82$

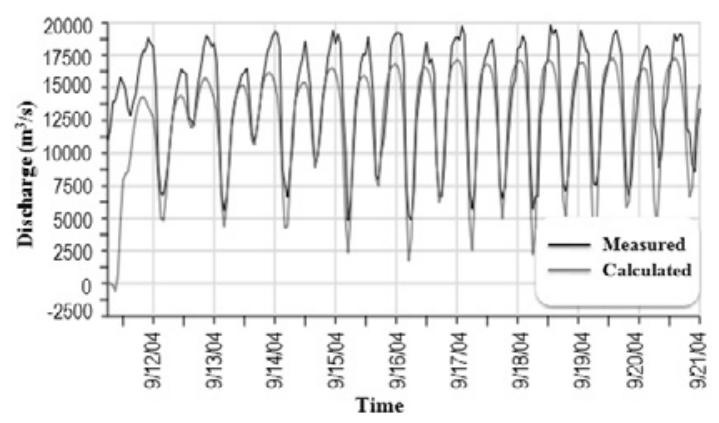

Fig. 19 Validation of calculated and measured flow at My Thuan station on September 2004 with NASH = 0.80

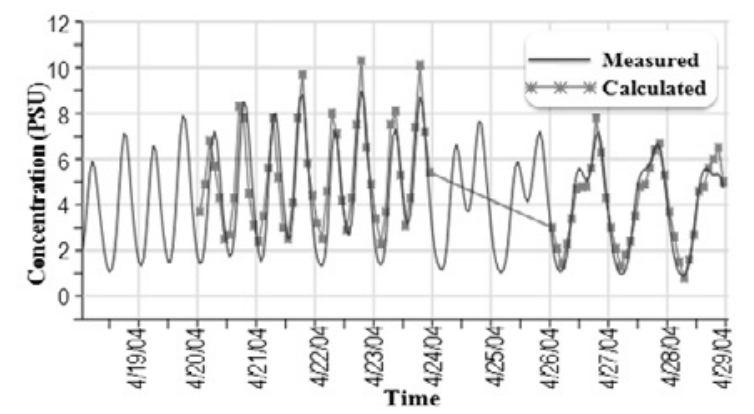

Fig. 20 Calibration of calculated and measured salinity at Dai Ngai station on April 2004 with NASH $=0.76$ 


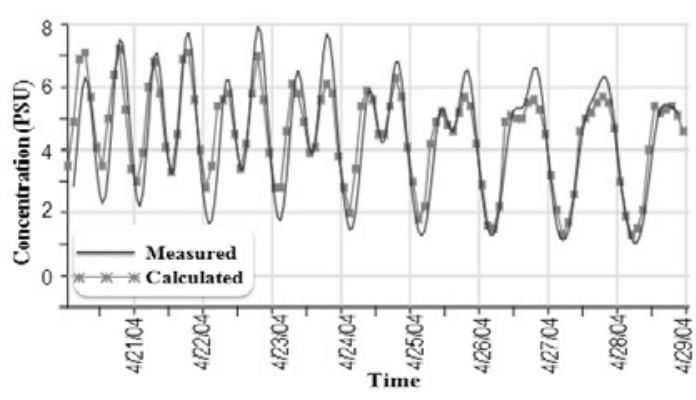

Fig. 21 Calibration of calculated and measured salinity at Tra Vinh station on April 2004 with $\mathrm{NASH}=0.79$

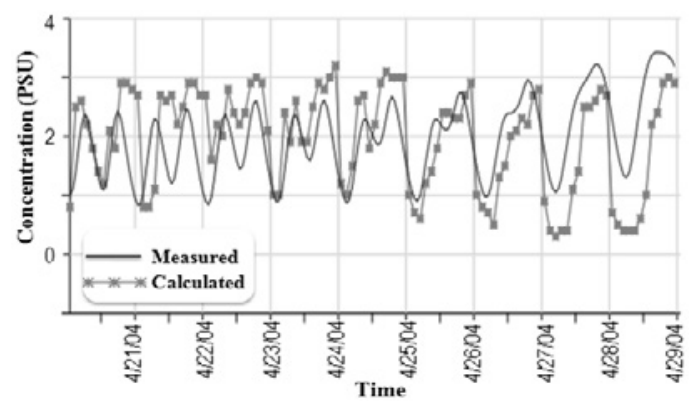

Fig. 22 Calibration of calculated and measured salinity at My Tho station on April 2004 with NASH $=0.74$

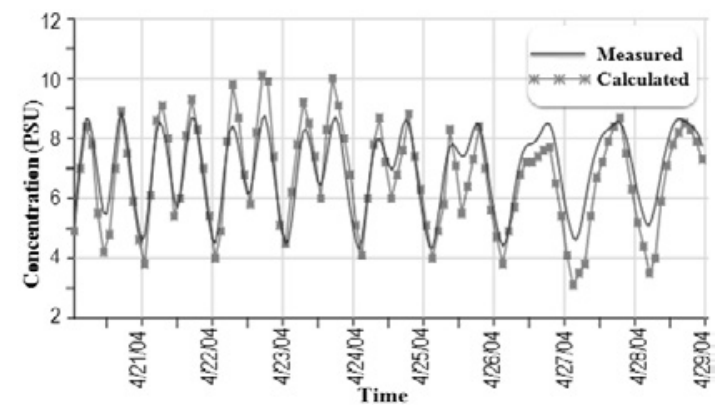

Fig. 23 Calibration of calculated and measured salinity at Hoa Binh station on April 2004 with $\mathrm{NASH}=0.75$

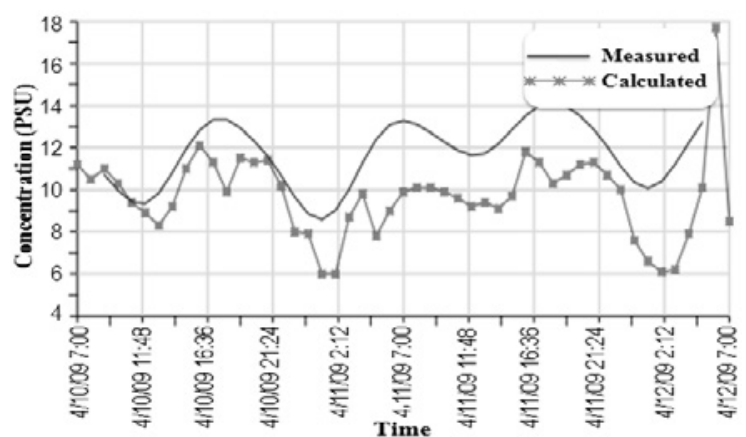

Fig. 24 Validation of calculated and measured salinity at $\mathrm{S} 1$ position on April 2009 with $\mathrm{NASH}=0.67$

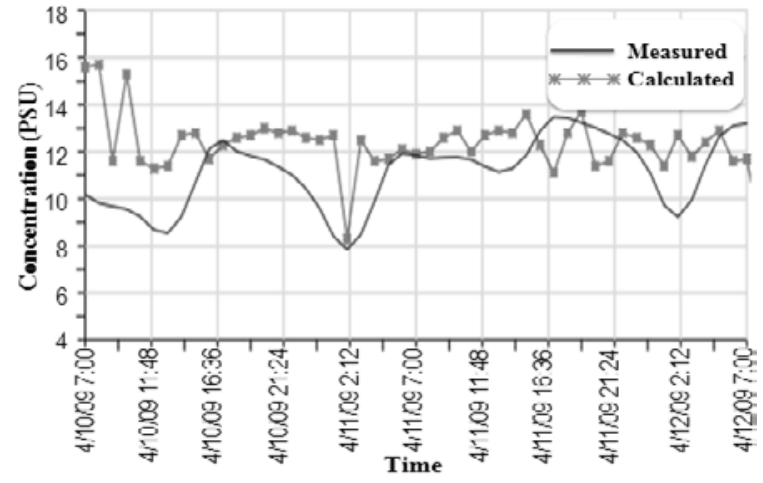

Fig. 25 Validation of calculated and measured salinity at S2 position on April 2009 with $\mathrm{NASH}=0.72$

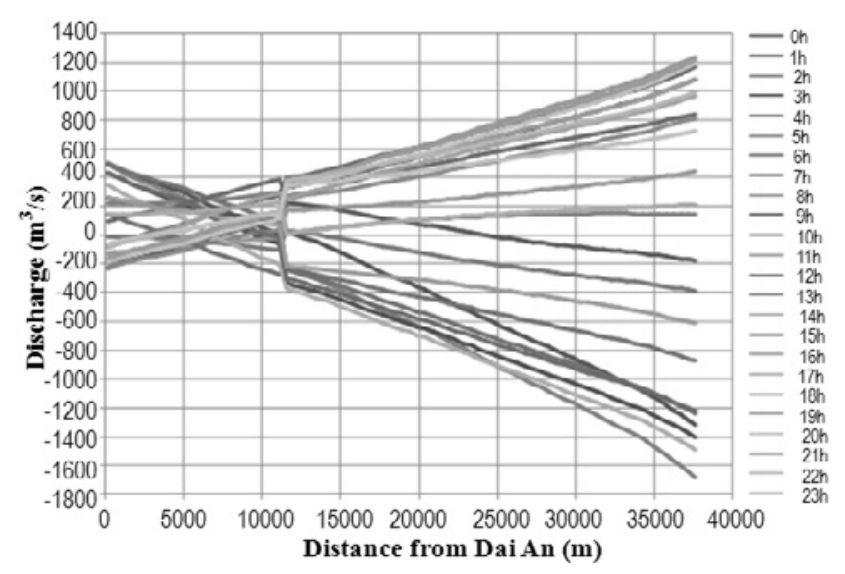

Fig. 26 Distribution of flow along Quan Chanh Bo channel in the 1 day simulation- In the case of existing condition (Scenario 1)

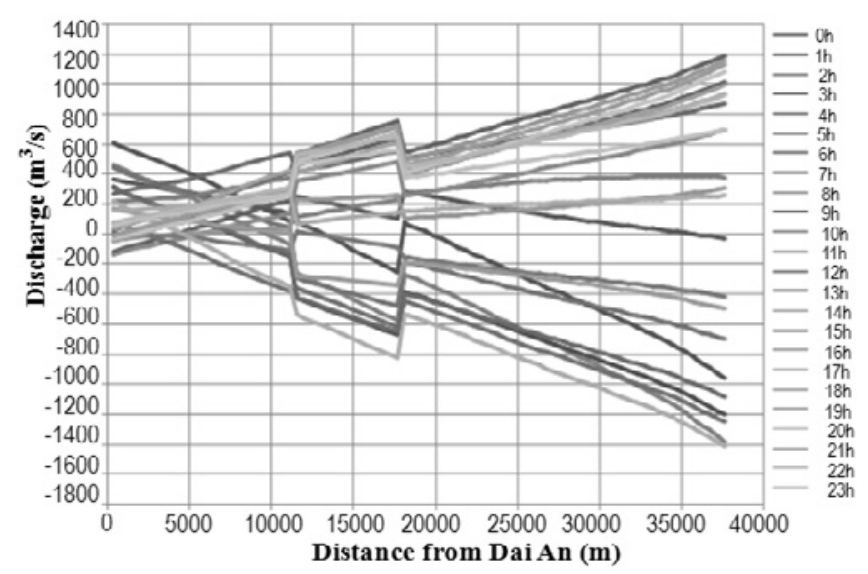

Fig. 27 Distribution of flow along Quan Chanh Bo channel in the 1 day simulation-In the case of after dredging (Scenario 1) 


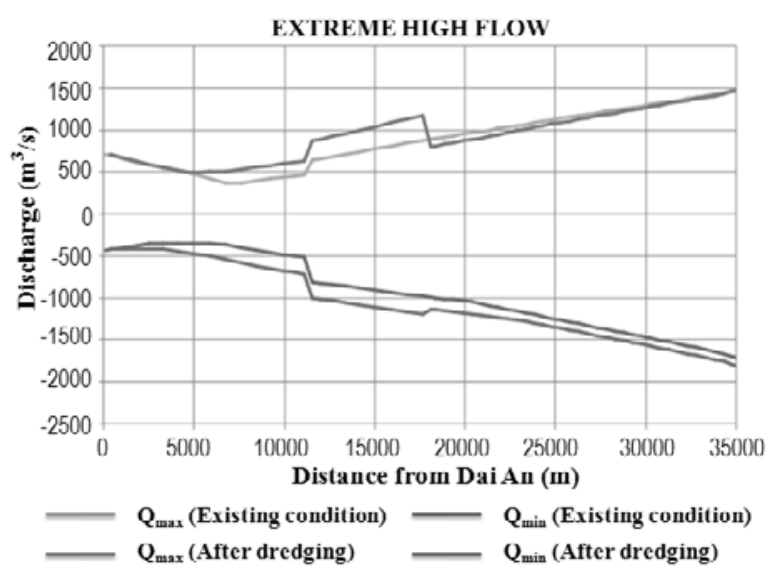

Fig. 28 Distribution of maximum and minimum flow along Quan Chanh Bo channel- In case of existing condition and after dredging (Scenario 1)

The result of an average flow in simulation period of 28 days is presented in Fig.29. An average inflow in the Quan Chanh Bo channel from Dai An estuary in the case of existing condition and after dredging corresponding is $8.3 \mathrm{~m}^{3} / \mathrm{s}$ and $46.9 \mathrm{~m}^{3} / \mathrm{s}$. An average outflow at Lang Chim estuary is $44.1 \mathrm{~m}^{3} / \mathrm{s}$. In the case of after dredging the flow value is $32.8 \mathrm{~m}^{3} / \mathrm{s}$. An average flow at Tat channel with direction into the sea has the value of $115.8 \mathrm{~m}^{3} / \mathrm{s}$. An average condition, the outflow from Tat channel is taken from Dai An estuary.

Scenario 2: Estimated distribution of flow along Quan Chanh Bo channel for 1 day simulation of exhausted flow in the existing conditions and after dredging are presented in Figs.30 and 31.

Fig.32 shows the distribution of maximum and minimum flow along Quan Chanh Bo channel in whole simulation period of 28 days (673 hours). After dredging the maximum outflow increased from $405 \mathrm{~m}^{3} / \mathrm{s}$ to $556 \mathrm{~m}^{3} / \mathrm{s}$ and the maximum inflow increased from $360 \mathrm{~m}^{3} / \mathrm{s}$ to $570 \mathrm{~m}^{3} / \mathrm{s}$ at Dai An estuary. The maximum outflow increased from $1,443 \mathrm{~m}^{3} / \mathrm{s}$ to $1,578 \mathrm{~m}^{3} / \mathrm{s}$ and the maximum inflow increased from $1,634 \mathrm{~m}^{3} / \mathrm{s}$ to $1,935 \mathrm{~m}^{3} / \mathrm{s}$ at Lang Chim estuary. The inflow and outflow at Tat channel corresponding is $406 \mathrm{~m}^{3} / \mathrm{s}$ and $335 \mathrm{~m}^{3} / \mathrm{s}$.

Similar to the case of flood, the flow changes can be explained by the tidal wave propagation process through Tat channel. It changes the surface slope and changes the flow distribution. The result of an average flow in simulation period of 28 days is presented in Fig.33. An average inflow in the Quan Chanh Bo channel from Dai An estuary in the case of existing condition and after dredging is $47.1 \mathrm{~m}^{3} / \mathrm{s}$ and $63.1 \mathrm{~m}^{3} / \mathrm{s}$ correspondingly. In the case of existing condition an average outflow at Lang Chim estuary is $52.8 \mathrm{~m}^{3} / \mathrm{s}$. In the case of after dredging the flow value increased $69.5 \mathrm{~m}^{3} / \mathrm{s}$. An average flow at Tat channel with direction into the sea has the value of $1.6 \mathrm{~m}^{3} / \mathrm{s}$ as expected in accordance smaller than in case of design flood. An average condition, the affect of Tat channel is relatively limited.

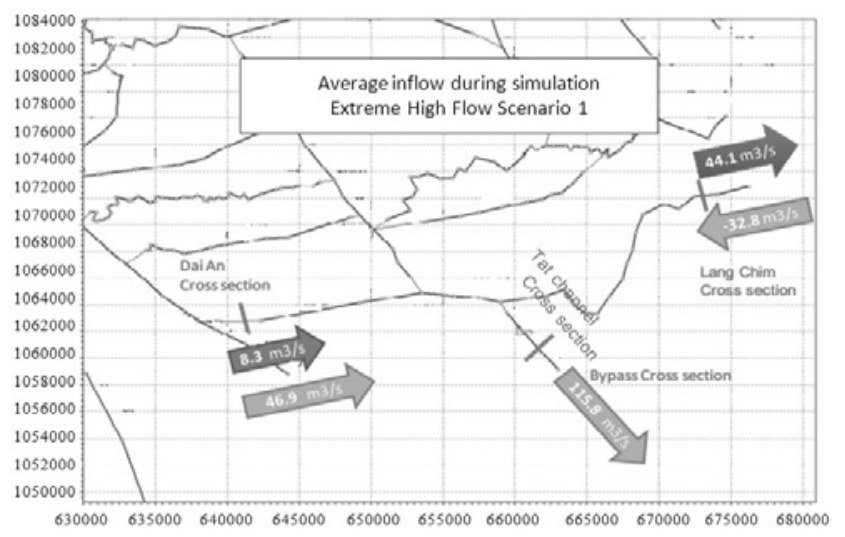

Fig. 29 An average flow before dredging (green), after dredging (yellow) (Scenario 1)

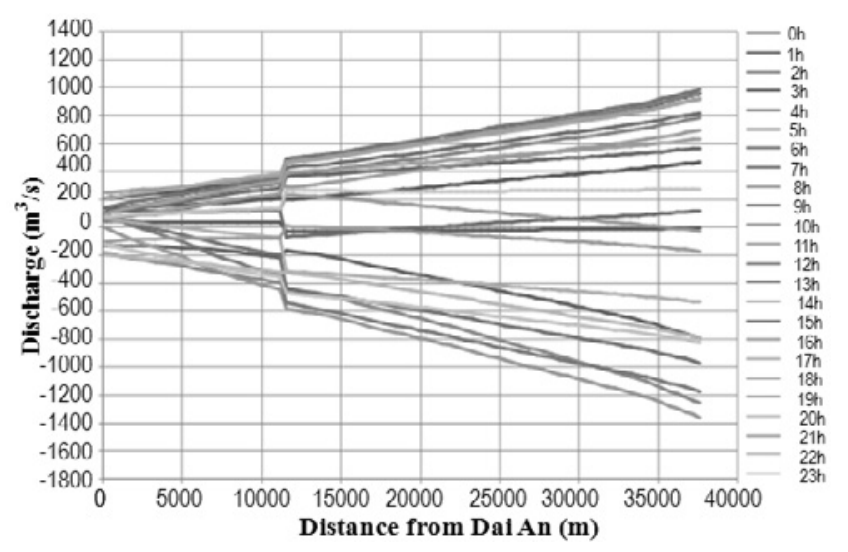

Fig. 30 Distribution of flow along Quan Chanh Bo channel in the 1 day simulation- In the case of existing condition (Scenario 2)

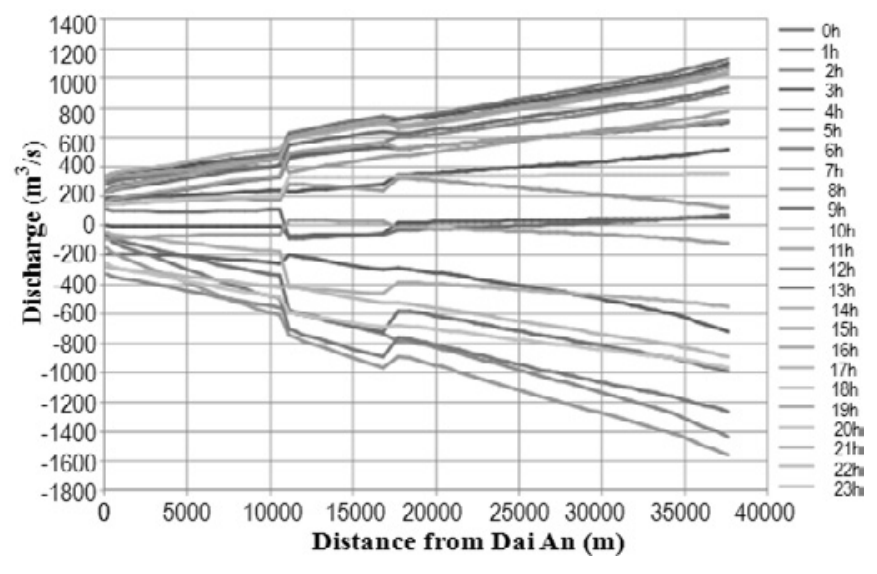

Fig. 31 Distribution of flow along Quan Chanh Bo channel in the 1 day simulation- In the case of after dredging (Scenario 2) 


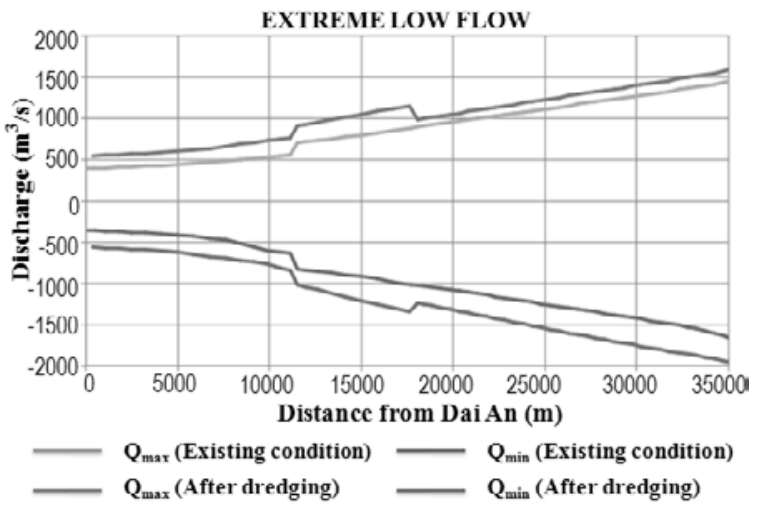

Fig. 32 Distribution of maximum and minimum flow along Quan Chanh Bo channel-In case of existing condition and after dredging (Scenario 2)

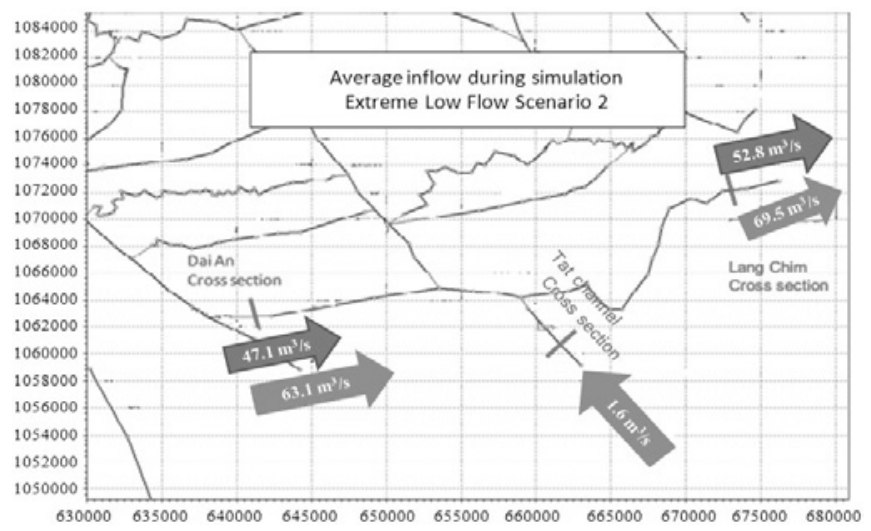

Fig. 33 An average flow before dredging (green), after dredging (yellow) (Scenario 2)

\section{CONCLUSIONS AND DISCUSSIONS}

A modeling-based assessment of the hydrodynamic and salinity intrusion in the Mekong River and estuary is described. The model was developed using a onedimensional hydraulic model and advection-dispersion model to simulate hydraulic regime in the river and salinity intrusion in the estuary areas. The model has been successfully applied to the river network in the Mekong River in Vietnam. The good agreements between simulated results and observed data demonstrate the capability of the model to simulate the tidal dynamics, wetting and drying processes, and salt intrusion in the estuary.

Comparing the calibrated and validated model results of the flow and the water level in 2000 and 2004 with measured data leads to the bellowed conclusions:

+ The database used to simulate the hydraulic parameters in the Mekong River Basin has acceptable reliability.
+ The results of calibrated and validated of flow, the water level and salinity in Mekong River Basin showed that the simulation results possess the high reliability, and the description rule correctness of flood dynamics in the study and vicinity area.

+ A comparison of calculation results from MIKE 11 HD model with the measured data on April 2009 shows that MIKE $11 \mathrm{HD}$ is compatible with the study area. Running time in the model is short, fast convergence, resulting computational stability and dependable.

+ The input data have acceptable reliability. The model is sufficiently reliable to apply simulation of hydraulic factors on the river network and predict impacts of salinity intrusion after dredging of new navigation routes.

An important issue arising after dredging Tat channel is increases the possibility salinity intrusion. This phenomenon will occur the strongest in the conditions the flow in the dry season. MIKE 11 model is used to calculate and simulate the salinity intrusion in 15 days for the case of design exhausted flow appearing in the upstream (Scenario 2) to review the effects of dredging. Distribution of salinity along Quan Chanh Bo channel is presented in Fig.34.

The results of salinity intrusion simulation in 15 days for the case of exhausted flow in the existing condition and after dredging showed that the impact of dredging only occurs in the scope of Quan Chanh Bo channel. The salinity at the Dai An and Lang Chim estuary is not changed after dredging. The maximum, average and minimum salinity concentration value along Quan Chanh Bo channel will be increasing the range of $2.0 \div$ 6.0PSU (Fig.34). Finally, the impact of dredging on salinity intrusion phenomenon is negligible; only occurs within the Quan Chanh Bo channel and does not affect the large river system. This modeling study provides a new insight into the circulation and salinity intrusion in the Mekong River estuary.

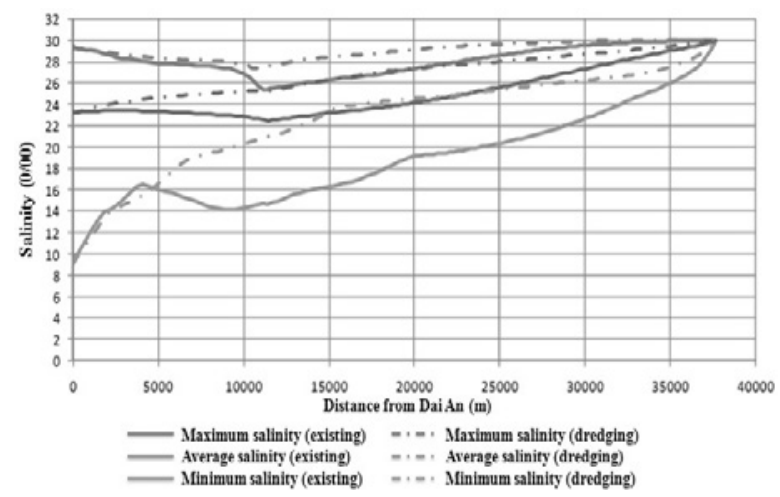

Fig. 34 The maximum, average and minimum salinity in the Quan Chanh Bo channel in the case of existing condition and after dredging 


\section{ACKNOWLEDGEMENTS}

This study was supposed by the PORSTCAST (Vietnam) and HMEC. The authors would like to thank Q. Thanh Tuyet for helping us collect the topography, meteorological, and measured data for this paper.

\section{REFERENCES}

Abbott, M.B. and Ionescu, F. (1967). On the numerical computation of nearly-horizontal flows. J. Hydraul. Res., 5: 97-117.

Abbott, M.B. and Cunge, J.A. (1975). Two-Dimensional Modeling of Tidal Deltas and Estuaries. Unsteady Flow in Open Channels 2. K. Mahmood and V. Yevjevich, eds. Fort Collins, Colorado, USA: Water Resour. Pub.: 763-812.

Alcausin, E.E. (1980). Salinity Intrusion in the Mekong Estuarine System. Master Thesis, Asian Institute of Technology, Bangkok, Thailand: 62-89.

Cunge, J.A. (1975). Two-Dimensional Modeling of Flood Plains. Unsteady Flow in Open Channels 2. K. Mahmood and V. Yevjevich, eds., Fort Collins, Colorado, USA: Water Resour. Pub.: 705-751.

Cong, N.C. (1992). Estimation of Mixing Conditions in the Mekong Estuarial System. Concluding Seminar on Mekong Delta Salinity Intrusion Study, Phase III, Ho Chi Minh City, Vietnam, March 1992, Mekong River Commission, Phnom Penh, Cambodia: 162174.

Dong, T.D. (2000). VRSAP model and its application. Proc. of the Workshop on Hydrologic and Environmental Modeling in the Mekong Basin, Phnom Penh, Cambodia (September): 236-245.

DHI (2007). MIKE 11 Reference Manual.

Eaton, A.D and Franson, M.A.H. (2005). Standard methods for the examination of water and wastewater. Washington, DC: U.S.A. American Pub. Health Assoc.

Kotera, A., Sakamoto, T., Nguyen, D.K., and Yokozawa, M. (2008). Regional Consequences of Seawater Intrusion on Rice Productivity and Land Use in Coastal Area of the Mekong River Delta. Jpn Agric Res. Q. (JARQ), 42(4): 267-274.

Le, S. (2006). Salinity intrusion in the Mekong Delta. Agriculture Publisher, Ho Chi Minh City, Vietnam: 387.

Mekong River Commission (MRC) (2004). Study on Hydro-Meteorological Monitoring for Water Quality Rules in The Mekong River Basin: Final Report, II (Supporting Report 2/2), WUP-JICA, Phnom Penh, Cambodia: 13-37.
Masaaki, T., Van, L.N., Oanh, T.T.K., Takao, T., Aymi, F., Kiyokazu, N., and Shigeo, M. (2007). Salt Water Intrusion in The Mekong River Estuary, Vietnam: Observation At Low Flow Season in May 2005. Science Report, Niigata Univ. (Geology), 22: 57-78.

Nash, J.E. and Sutcliffe, J.V. (1970). River flow forecasting through conceptual models part I-A discussion of principles, J. Hydro., 10 (3): 282-290.

NEDECO (1991a). Review and Assessment Reports. Outline Inception Report, Government of Vietnam/State Planning Committee/World Bank/Mekong Secretariat (Mekong River Commission, Phnom Penh, Cambodia)/United Nations Development Program: 69-78.

Nguyen, A.N. and Nguyen, V.L. (1999). Salt water intrusion disaster in Vietnam. Publication of UNDP Project No VIE/97/002, Ho Chi Minh City, Vietnam: 68.

Price, R.K. (2009). Volume-conservative nonlinear flood routing. J. Hydraul. Engrg., 135(10): 838-845.

Quang, L.X. and Ngoc, N.V. (1987). Numerical modeling for salinity intrusion by Implicit Finite Difference Method - Case study: Mekong estuarine river system. Proc. Concluding Seminar on Mekong Delta Salinity Intrusion Study, Phase II, Ho Chi Minh City, Vietnam (March), Mekong River Commission, Phnom Penh, Cambodia: 122-132.

Sam, L. (2006). Salinity Intrusion in the Mekong Delta. Agric. Pub. House, Ho Chi Minh City: 123-135.

Shooshtari, M.M. (2008). Principles of flow in open channels. Shahid Chamran University Press, 15(2): 643-745.

Thoi, N.H. (1987). Water Resources Utilization for Irrigation in Tidal Zone, Tam Phuong Project, the Mekong Delta. Master Thesis, Asian Institute of Technology, Bangkok, Thailand: 45-58.

Thoi, N.H. (1993). A methodology for the assessment of surface water resources in tidal areas. Proc. of the Intl. Congress on Modeling and Simulation, Perth, Australia: 1175-1180.

Thoi, N.H. (1994). Water Resources Utilization in Tidal Areas: The Mekong Delta. D. Eng. Dissertation, Asian Institute of Technology, Bangkok, Thailand: 12-56.

Tingsanchali, T. and Thoi, N.H. (1993). Water resources utilization in Tam Phuong Tidal Irrigation Project, Vietnam. Proc. of the Inter. Conf. on Environmentally Sound Water Resources Utilization, Bangkok, Thailand (November): III-119 - III-128.

Thuy, D.T. and Dac, N.T. (2000). Modeling of flow and salinity in the Mekong Delta by SAL99 model. Proc. of the Workshop on Hydrologic and Environmental Modeling in the Mekong Basin, Phnom Penh, 
Cambodia: 225-235.

Van Parreeren, D. (1974). Computer Program for the One-Dimensional Tidal Model of the Mekong Delta. Mekong Committee, Bangkok, Thailand (Mekong River Commission, Phnom Penh, Cambodia): 10-72.

Wolanski, E. (1996). Estuarine processes in the Mekong River Estuary, Vietnam: Will they hinder economic development? Proc. of the Workshop on Development Dilemmas in the Mekong Sub-region,
Melbourne, Australia: 248-249.

Zanobetti, D., Lorgere, H., Presismann, A., and Cunge, J.A. (1970). Mekong Delta Mathematical Program Construction. J. Waterways and Harbors Div., Proc. of the American Society of Civil Engineers, ASCE, 96(WW2): 181-199. 